\title{
The Development of a Special Purpose Drink Based on Nut Raw Materials
}

\author{
Zhanna Victorovna Novikova ${ }^{1 *}$, Dmitry Sergeevich Lavrinovich ${ }^{2}$, Sophie \\ Mikhailovna Sergeeva ${ }^{1}$ and Anton Alexeyevich Maksimkin ${ }^{1}$ \\ ${ }^{1}$ Moscow State University of Food Production, Moscow, Russia \\ ${ }^{2}$ National University of Science and Technology "MISIS", Moscow, Russia \\ ORCID
}

Zhanna Victorovna Novikova; 0000-0002-7358-037

Corresponding Author: Zhanna

Victorovna Novikova; email:

novikova@mgupp.ru

\section{Dates}

Published 13 January 2022

Publishing services provided by Knowledge E

(c) Zhanna Victorovna Novikova et al. This article is distributed under the terms of the

which permits unrestricted use and redistribution provided that the original author and source are credited.

Selection and Peer-review under the responsibility of the 8th Scientific and Practical Conference Conference Committee.
Abstract. To support health, efficiency and active longevity, a person needs to provide the body with the micronutrients necessary for metabolic processes. They must consume food in quantities that correspond to the physiological needs of the individual. Analyses of consumer demand have found that the human diet throughout life often includes dairy products.However, whole milk is often poorly tolerated by both the elderly and people with lactose intolerance (hypolactasia).This article examined the selection of alternative energy sources, focusing on the example of a drink that uses plant raw materials. Thus, the recipe of a new fermented drink based on nut raw materials was developed. The optimization of the hydromodule for the drink preparation from peanuts and hazelnuts, according to the content of the main food components and organoleptic quality indicators, was carried out. The chemical composition of the developed drink was established, a portion of which met $20 \%$ of the daily recommended value of vitamin B1, $16.8 \%$ of the daily value of niacin, and $15 \%$ and $19 \%$ of the daily value of iron and magnesium, respectively. The possibility of producing a fermented drink with nut raw materials as a complete replacement of cow's milk was therefore shown to be justified.

Keywords: specialized food, probiotic, vegetable raw materials, fermented drink, nuts

\section{Introduction}

The main factor affecting human health is nutrition. The results of many studies confirm that preventive and specialized nutrition, which contains a complex of macro - and micronutrients necessary for body, including biologically active substances, can slow down the aging of the body and reduce the risk of developing various diseases by up to $30 \%$ [7].

Nutritional correction of the lack of macro - and micronutrients can be carried out with the help of specialized food products with increased nutritional value and content of biologically active substances.Taking into account the connection of nutrition with human diseases, scientists classify several groups, representatives of one which suffer from diseases caused by food intolerance (intestinal fermentopathy, food Allergy, food pseudo-Allergy that does not have an immune stage of development, psychogenic food 
intolerance, and others).In the diet of people in this group, the ratio between plant and animal proteins should be observed in the proportion of 1:1. in this case, one of the animal protein sources is poultry, fish [4].

However, there is a group of people who refuse to eat animal products, including milk, for ethical or religious reasons. Therefore, both in the first and in the second cases, alternative foods containing animal proteins or analogs close to them in their biological value are necessary for a full diet [2, 3].

Accordingto technical regulations of the customs Union 021/2011 'About food safety', specialty beverages are beverages that have established requirements for the content and ratio of individual substances and components, and/or that have changed the content or ratio of individual substances relative to their natural content [9].

The segment of the specialty drinks market is developing dynamically. There are known fortified beverages based on juice, milk, pectin-containing and other bases [8].

Taking into account the nutritional characteristics of various population groups, namely: reduced tolerance to simple carbohydrates, preference for products that normalize the intestinal microflora and are rich in fiber, refusal to use animal products, and consumers' enthusiasm for experimenting with new ingredients and new tastes, also was decided to develop a specialized drink based on nuts using probiotic cultures.

The inclusion of probiotic products in the various age groups diet of the population with their regular use provides a significant improvement in digestion, stimulating immune processes, reducing the allergic mood of the body, contributes to the correct formation of microflora[5].

Based on the analysis of the chemical composition of nut raw materials presented in table 1, it was found that the largest amount of biologically active substances is contained in peanuts, hazelnuts and almonds. They are rich in phosphorus, potassium, iron, vitamins $b$ and $E$, contain few carbohydrates, and more than $50 \%$ of carbohydrates are represented by fiber (Table 1).

Drinks based on almonds are quite widespread (the most famous brands are: Altro, Milk, Fresh, 365 DETOX, JUMI), so the authors' interest was to develop a specialized drink based on hazelnuts and peanuts.

The purpose of this study was to study the possibility of using nut raw materials in the production technology of a specialized beverage based on vegetable raw materials with high consumer properties and quality indicators. 
TABLE 1: The chemical composition comparative analysis of nuts.

\begin{tabular}{|c|c|c|c|c|c|}
\hline \multirow[t]{2}{*}{ Indicator } & \multicolumn{5}{|c|}{ Content in $100 \mathrm{~g}$ of nuts } \\
\hline & peanut & walnut & hazelnut & cashew & almond \\
\hline Humidity, \% & 6,50 & 4,07 & 5,31 & 5,20 & 4,41 \\
\hline Energy value, kcal & 567 & 654 & 628 & 553 & 579 \\
\hline Proteins, g. & 25,80 & 15,23 & 14,95 & 18,22 & 21,15 \\
\hline Fat, g. & 49,24 & 65,21 & 60,75 & 43,85 & 49,93 \\
\hline Carbohydrates, g. & 16,13 & 13,71 & 16,7 & 30,19 & 21,55 \\
\hline Fiber, g. & 8,50 & 6,70 & 9,70 & 3,30 & 12,50 \\
\hline \multicolumn{6}{|l|}{ Vitamins } \\
\hline Vitamin B1, mg & 0,640 & 0,341 & 0,643 & 0,423 & 0,205 \\
\hline Vitamin B2, mg & 0,135 & 0,150 & 0,113 & 0,058 & 1,138 \\
\hline Vitamin B6, mg & 0,348 & 0,537 & 0,563 & 0,417 & 3,618 \\
\hline Niacin, mg & 12,070 & 1,125 & 1,800 & 1,062 & 3,618 \\
\hline Vitamin E, mg & 8,33 & - & 15,03 & 0,90 & 25,63 \\
\hline \multicolumn{6}{|l|}{ Mineral substance } \\
\hline Magnesium, mg & 168 & 158 & 163 & 292 & 270 \\
\hline Potassium, mg & 705 & 441 & 680 & 660 & 733 \\
\hline Iron, mg & 4,58 & 2,91 & 4,70 & 6,68 & 3,71 \\
\hline
\end{tabular}

\section{Materials and methods.}

All types of raw materials used in the work meet the requirements of current regulatory documents: Interstate standard, Technical conditions, Sanitary-hygienic rulesandwere acceptable in the preparation of beverages. The following raw materials were used for research:a peanutbylnterstate standard 31784-2012 (ISO 6478:1990); a hazelnutbyInterstate standard 16834-81; sugarbylnterstate standard 33222-2015; probiotic Bifidum Backdraw- Interstate standardP 56139-2014 (TY 9229-025-51070597-2007).

For the experimental part of the work we used generally accepted methods of research of quality indicators.

Hazelnut- the fruit of a large hazelnut, belongs to the order bucotsvetnykh, family Corylaceae (hazelnut), and is intended for fresh consumption and industrial processing. Hazelnuts are rich in nutrients. Nut kernels contain vitamins B1, B2, E, minerals: iron, potassium, phosphorus, calcium, zinc.Hazelnuts, like many nuts, are high in protein. The amino acid composition of hazelnuts differs in the total level of the total amount up to $35 \%$. It should be noted that hazelnuts exceed soy proteins by $20 \%$ in terms of threonine, leucine, isoleucine, valine and phenylalanine content. Carbohydrates are represented by starch, polysaccharides, the proportion of soluble sugars is much lower than carbohydrates. 
Peanuts are the seed of a herbaceous plant in the legume family. Peanuts are very nutritious and full of various minerals and vitamins. Peanuts contain macronutrients such as potassium, phosphorus, magnesium, and trace elements such as iron, zinc, manganese, copper and selenium, vitamins E, B1, B2, B4, B5, B6, B9 and PP. Peanuts are also a source of phenolic compounds with high antioxidant activity.

\section{Results and their discussion}

Creation of beverage recipes based on raw nut materials is based on the study of changes in quality indicators depending on the ratio of the components of nuts to water. The best indicators of nutritional value were observed in the mixture with a 1to 2 hydronic module, while the mixture of this hydronic module had a pronounced nutty flavor, while with a hydronic module of 1to 3 it was softer, and the content of fat and protein was only slightly lower. However, an increase in the hydromodule in a ratio of 1 to 4 significantly impairs the organoleptic characteristics in terms of taste. Taking these indicators into account, a 1 to 3 hydromodule was used to develop the beverage recipe.

To prepare a drink from a mixture of nuts, weighed portions of peanuts and hazelnuts were taken in the ratios of 40 to 60,50 to 50 , and 60 to 40 , then the drink was prepared with a 1 to 3 hydromodule. The indicators of cow's milk were used as a control sample. The resulting mixtures were evaluated in terms of food and energy values. The closest to the control in terms of protein content was a mixture consisting of $60 \%$ peanuts and $40 \%$ hazelnuts. At the same time, the ash content was significantly higher than that of cow, which indicates a high content of minerals in the mixture.

In order to enrich the experimental sample and give it a functional orientation, it was decided to introduce the probiotic Bifidum Bakzdrav (TU 9229-025-51070597-2007) into the recipe, the active substances of which are probiotic cultures: Streptococcus thermophilus, Bifidobacterium adolescentis, Bifidobacterium bifidium, Bifidobacterium breve, Bifidobacterium animails, Bifidobacterium longum, Bifidobacterium parvolorum, Bifidobacterium infantis, Lactobacillus reuteri, Lactobacillus delbrueckii subsp. bulgaricus, Lactobacillus rhamnosus, Lactobacillus sasei, Lactobacillus gasseri, Lactobacillus salivarius. In fact, these are natural symbiotic bacteria that inhabit the gastrointestinal tract and have a normalizing effect on the quantitative and qualitative composition of the human intestinal microflora. [1]

The technology of preparing a specialized drink based on nuts consisted of the following technological operations: 


\section{TABLE 2: Chemical composition of the drink}

\begin{tabular}{|c|c|c|c|c|}
\hline Indicators & $\begin{array}{l}\text { Daily } \\
\text { rate }\end{array}$ & $\begin{array}{l}\text { Content in } 100 \\
\mathrm{ml}\end{array}$ & $\begin{array}{l}\text { Contents in } 1 \text { serving } \\
(200 \mathrm{ml})\end{array}$ & $\begin{array}{l}\% \text { of daily rate per } \\
\text { serving }\end{array}$ \\
\hline Protein, g. & 68 & 2,96 & 5,92 & $8,7 \%$ \\
\hline Fats, g. & 77 & 4,79 & 9,58 & $12,4 \%$ \\
\hline Carbohydrates, g. & 335 & 8,41 & 16,82 & $5,0 \%$ \\
\hline vitamin $B_{1}$, mg & 1,5 & 0,210 & 0,420 & $28,0 \%$ \\
\hline vitamin $B_{2}$, mg & 1,8 & 0,048 & 0,096 & $5,3 \%$ \\
\hline vitamin $B_{6}$, mg & 2,0 & 0,130 & 0,260 & $13,0 \%$ \\
\hline Niacin, mg & 20,00 & 1,68 & 3,36 & $16,8 \%$ \\
\hline Potassium, mg & 2500 & 178,70 & 357,40 & $14,3 \%$ \\
\hline Magnesium, mg & 400 & 38,55 & 77,10 & $19,3 \%$ \\
\hline Iron, mg & 12 & 0,91 & 1,82 & $15,2 \%$ \\
\hline
\end{tabular}

1. the Nuts were washed until the turbid or brown color disappeared; soaked in water (hazelnuts - for 12 hours; peanuts - for 6 hours); crushed for 3-5 minutes.

2. The resulting mixture was heated to $40^{\circ} \mathrm{C}$, filtered, separating the solid phase.

3. the Mixture was transferred to a glass sterilized container and added probiotic; then placed in a thermostat at $40{ }^{\circ} \mathrm{C}$ for $10-12$ hours.

4. after fermentation, the product was placed in a refrigerator for cooling.

Studies to determine the optimal recipe composition of a specialized drink with high organoleptic quality indicators have confirmed that the amount of probiotic added to the recipe should not exceed $0.2 \%$. The resulting sample had an attractive appearance, a harmonious nutty taste with a light delicate sourness, and a pleasant aroma.

Regulated quality indicators were studied in the resulting sample. The content of the main food substances in the finished drink was determined by standard methods. The results are shown in table $2[6,10]$.

It has been experimentally determined that a serving of the developed nut drink satisfies $8 \%$ of the daily value of protein, $12 \%$ of fat and $5 \%$ of carbohydrates. As can be seen from the results, the finished product contains $20 \%$ of the daily value of vitamin B1, $16.8 \%$ of the daily value of niacin, 15 and $19 \%$ of the daily value of iron and magnesium, respectively.

To determine the shelf life, in accordance with SanPiN 2.3.2.1324-03 and MUK 4.2.1847-04, the drink was stored in a refrigerator at a temperature of $+2-+4{ }^{\circ} \mathrm{C}$ for 8 days. The biological safety of the taken samples was monitored on the 3rd, 5th and 8th days of storage and inoculated. The results are shown in Table 3.

When storing a specialized drink on the 5th day, 3 colonies of yeast and 1 colony of molds were found, on the 8th day - 15 and 8 colonies, respectively. Coliformsand 
TABLE 3: Microbiological indicators of the drink during storage.

\begin{tabular}{|c|c|c|c|c|}
\hline \multirow{2}{*}{$\begin{array}{l}\text { Defined } \\
\text { indicators }\end{array}$} & \multicolumn{3}{|c|}{ Kesearch results } & \multirow{2}{*}{$\begin{array}{l}\text { The value of the per- } \\
\text { missible level }\end{array}$} \\
\hline & $3^{r d}$ day & $5^{\text {th }}$ day & $8^{\text {th }}$ day & \\
\hline QMA\&OAMO & Not found & Not found & Not found & $5 \times 10^{4}$ \\
\hline Coliforms & Not found & Not found & Not found & Not allowed in $1.0 \mathrm{~g}$ \\
\hline Yeast & Not found & 3 & 15 & $\begin{array}{l}\text { No more than } 10 \\
\text { CFU/g }\end{array}$ \\
\hline Molds & Not found & 1 & 8 & $\begin{array}{l}\text { No more than } 10 \\
\text { CFU/g }\end{array}$ \\
\hline
\end{tabular}

QMA\&OAMO bacteria were not detected. The organoleptic characteristics of the drink deteriorated on the fourth day, when a pronounced sour smell and taste were noticed that were not typical for this type of product. Thus, it is allowed to store a specialized drink for 3 days at a temperature of $4 \pm 2^{\circ} \mathrm{C}$.

\section{Conclusion}

According to the results of the research, it is concluded that hazelnuts and peanuts can be used in the production of a specialized drink from vegetable raw materials intended for feeding people with food intolerance to cow's milk. The developed drink is characterized not only by high organoleptic quality indicators, but also by a balanced physical and chemical composition, the presence of biologically active components.

\section{References}

[1] Gradoboeva AV, Lavrova LY. Technology of production of yoghurts from nut milk and their evaluation by organoleptic quality indicators. Innovative technologies in the food industry and public catering. Yekaterinburg: Ural State Econ. University, 2017.

[2] Gurina AE. Pancreatic dysfunction in lactase deficiency and celiac disease. Vladikavkaz Medico-Biological Bulletin 2013. 2013;26:95-102.

[3] Lavrova LY. On the issue of creating innovative products at catering enterprises of the Ural region. Innovative technologies in the field of food, service and trade.Materials of the V International Scientific-Practical Conf.; Yekaterinburg, Russia;2018 October 15-16. Yekaterinburg: USUE Publishing House; 2018.

[4] Lavrova LY. Development of technology and recipes for organic products based on vegetable milk. Food Industry.2019;4(2):43-50. 
[5] Leonidov DS. Prebiotics: Strategy for the development of health products. Meet technology. 2011. 9(105). 48-49

[6] Onishchenko G. MR 2.3.1.2432-08. Norms of physiological needs for energy and nutrients for various groups of the population of the Russian Federation. Moscow, GU NII pitaniya RAMN, 2009.

[7] Onishchenko GG, Tutelyan VA. State policy of healthy nutrition of the population: Tasks and ways of implementation at the regional level. Moscow: Geotar-Media; 2009.

[8] Smirnova EA, Kochetkova AA. The market for functional products. Dairy Industry.2011;2:63-66.

[9] TR CU 021/2011. Technical regulations of the Customs Union. On food safety (as amended and supplemented, entered into force on July 11, 2020). Text: electronic.ConsultantPlus. 2019/12/24 Available from: http://www.consultant.ru/document/cons_doc_LAW_124768/.

[10] Tutelyan VA. On the norms of physiological needs for energy and nutrients for various groups of the population of the Russian Federation. Questions of nutrition. 2009;78(1):4-15.

[11] Tutelyan VA. Chemical composition and caloric content of Russian food products. Moscow: DeLiPlus; 2012. 